\title{
Syringomatous Structures in Extramammary Paget Disease: A Potential Diagnostic Pitfall
}

Konstantinova, Anastasia M ; Hayes, Malcolm M ; Stewart, Colin J R ; Plaza, Jose A ; Michal, Michal ; Kerl, Katrin ; Kazakov, Dmitry V

\begin{abstract}
Primary extramammary Paget disease (EMPD) is a form of intraepithelial adenocarcinoma. Different morphological changes may accompany EMPD, including the presence of syringoma-like structures. The authors report 10 cases of EMPD, all of which manifested syringoma-like structures within the dermis both in areas involved by the carcinoma and beyond, including at the margins of the excisions. All patients were women, whose ages ranged from 49 to 93 years (median 75 years). The possible pathogenesis of the syringoma-like lesions is discussed. Awareness of these structures in vulvectomy specimens for EMPD is important to prevent misinterpretation of the syringoma-like lesions as an invasive component of the EMPD.
\end{abstract}

DOI: https://doi.org/10.1097/DAD.0000000000000497

Posted at the Zurich Open Repository and Archive, University of Zurich

ZORA URL: https://doi.org/10.5167/uzh-130111

Journal Article

Published Version

Originally published at:

Konstantinova, Anastasia M; Hayes, Malcolm M; Stewart, Colin J R; Plaza, Jose A; Michal, Michal; Kerl, Katrin; Kazakov, Dmitry V (2016). Syringomatous Structures in Extramammary Paget Disease: A Potential Diagnostic Pitfall. American Journal of Dermatopathology, 38(9):653-657.

DOI: https://doi.org/10.1097/DAD.0000000000000497 


\title{
Syringomatous Structures in Extramammary Paget Disease: A Potential Diagnostic Pitfall
}

\author{
Anastasia M. Konstantinova, MD, PhD, * + Malcolm M. Hayes, MB, MMed (Anat Path), FRCPath, $\neq$ \\ Colin J. R. Stewart, FRCPA, § Jose A. Plaza, MD, \ Michal Michal, MD, |** Katrin Kerl, MD, †† \\ and Dmitry $V$. Kazakov, MD, PhD** + \%
}

\begin{abstract}
Primary extramammary Paget disease (EMPD) is a form of intraepithelial adenocarcinoma. Different morphological changes may accompany EMPD, including the presence of syringoma-like structures. The authors report 10 cases of EMPD, all of which manifested syringoma-like structures within the dermis both in areas involved by the carcinoma and beyond, including at the margins of the excisions. All patients were women, whose ages ranged from 49 to 93 years (median 75 years). The possible pathogenesis of the syringomalike lesions is discussed. Awareness of these structures in vulvectomy specimens for EMPD is important to prevent misinterpretation of the syringoma-like lesions as an invasive component of the EMPD.
\end{abstract}

Key Words: extramammary Paget disease, syringoma, syringomalike structures, vulva

(Am J Dermatopathol 2016;38:653-657)

\section{INTRODUCTION}

Primary extramammary Paget disease (EMPD) is a form of intraepithelial adenocarcinoma of uncertain histogenesis. Various origins have been proposed including apocrine glands, eccrine glands, hair follicles, ${ }^{1-8}$ anogenital mammary-like glands, Toker cells, or pluripotential stem cells in the epidermis. ${ }^{9-14}$ Unlike mammary Paget disease, EMPD is seldom associated with an underlying ductal carcinoma in situ or invasive carcinoma except for those cases that arise within an anogenital mammary-like glands. ${ }^{15-18}$ In contrast, syringoma is a benign adnexal neoplasm occurring in the superficial dermis. ${ }^{19}$ Both lesions occur on the vulva and perineal skin but, there is no known relationship between

From the *Department of Pathology, Clinical Research and Practical Center for Specialized Oncological Care, Saint Petersburg, Russia; †Department of Pathology, Medical Faculty, Saint-Petersburg State University, Saint Petersburg, Russia; $\$$ Department of Pathology, BC Cancer Agency, Vancouver, British Columbia, Canada; §Department of Histopathology, King Edward Memorial Hospital, Perth, Australia; 9 Department of Pathology, Division of Dermatopathology, Medical College of Wisconsin, Milwaukee, WI; ||Sikl's Department of Pathology, Bioptical Laboratory, Pilsen, Czech Republic; **Sikl's Department of Pathology, Medical Faculty in Pilsen, Charles University in Prague, Pilsen, Czech Republic; and $\uparrow \dagger$ Department of Dermatology, University Hospital Zurich, Zurich, Switzerland.

The authors declare no conflicts of interest.

Reprints: Dmitry V. Kazakov, MD, PhD, Sikl's Department of Pathology, Charles University Medical Faculty Hospital, Alej Svobody 80, 30460 Pilsen, Czech Republic (e-mail: kazakov@medima.cz).

Copyright $(2016$ Wolters Kluwer Health, Inc. All rights reserved. them. In the vulva, syringomas are often associated with chronic pruritis, also a common symptom of EMPD. ${ }^{20,21}$

During histopathological examination of vulvectomy specimens from 10 patients with EMPD we encountered small syringoma-like foci in the dermis beneath the involved epidermis and occasionally beyond the margin of the EMPD. Our study is focused on these unusual glandular structures, which could be interpreted as invasive carcinoma and therefore represent a diagnostic pitfall for pathologists unaware of their existence.

\section{MATERIALS AND METHODS}

The 10 patients constituting the subject of this report were found among 98 cases of EMPD in the joint consultation and institutional files of the authors. Clinical information was obtained from the patients' physicians and from review of case records. Each case was stained with hematoxylin and eosin and mucicarmine, and immunohistochemical staining for CK7 and p63 was performed on 9 blocks from 7 patients.

In 3 cases, syringomatous change was seen both in the initial biopsy and in subsequent specimens demonstrating local recurrence of the EMPD. A total of 13 specimens were examined comprising 10 vulvectomies with the number of tissue blocks ranging from 14 to 27 , and 3 wide local excisions sampled in 4, 13, and 18 blocks, respectively. Overall, syringomatous structures were recognized in 31 of 247 blocks studied (Table 1).

\section{CLINICAL DATA}

All patients were women whose ages ranged from 49 to 93 years. Eight patients presented with a newly diagnosed EMPD, whereas the other 2 had a previous history of EMPD treated by various modalities (Table 1). All patients clinically manifested flat or slightly elevated erythematous or white-gray areas, with some scaling, excoriations, and crust consistent with primary EMPD (Fig. 1). In 1 patient, small papules were present within and outside the affected areas, but these proved to be infundibular cysts on histology. None of the patients had had a history of a carcinoma in the urogenital or gastrointestinal tract that might have suggested secondary skin involvement from these sites. One patient had a history of vulvar squamous cell carcinoma. 
TABLE 1. Main Clinical Features of the Patients

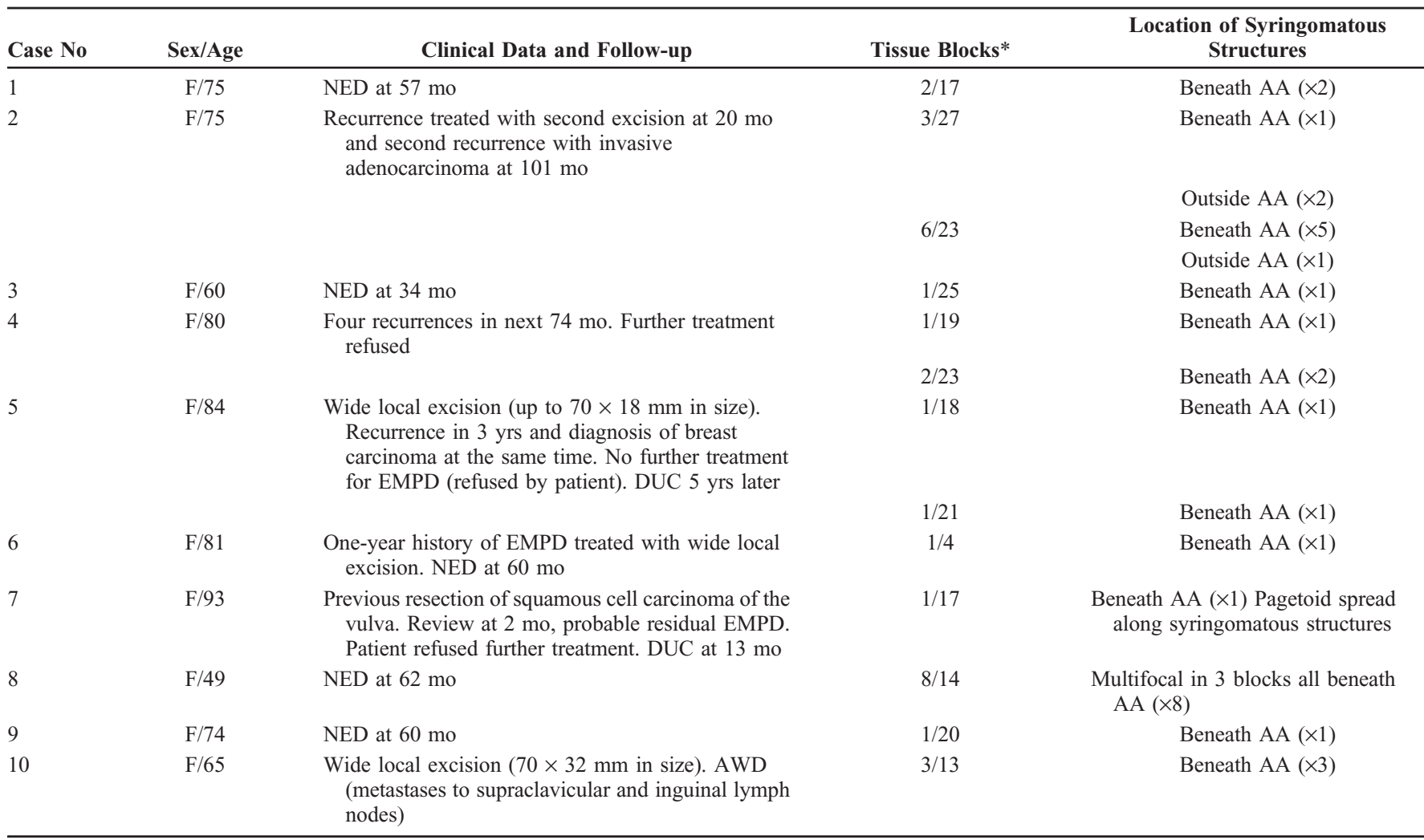

NED no evidence of disease.

AWD alive with disease

DUC death of unknown (case 5) or unrelated (case 7) cause.

AA areas affected by the EMPD.

*The first number indicates the number of tissue blocks in which the syringomatous structures were identified. The number after slash indicates the total number of blocks available from case.

\section{MICROSCOPIC FEATURES}

The typical microscopic features of EMPD were present in all cases. These included an intraepithelial spread of cells with ample cytoplasm distributed singly and in small clusters. In all cases, small gland-like elements formed by the neoplastic cells were identified within the epidermis. In 2 cases, malignant glandular elements were seen lying free in the upper dermis consistent with microinvasion. Apart from these neoplastic glandular elements, all cases showed benign-looking dermal ductal structures resembling classical syringoma (Fig. 2). These syringomatous foci were present both beneath the areas affected by the EMPD and outside them, sometimes being noted in sections taken from the margins of excision. The syringomatous structures appeared as a cluster of benign looking ductal elements with attenuated epithelium, including focal tadpole-like appearances. Their connection to an eccrine secretory unit could be traced on serial sections (Fig. 3). In 1 case, syringomatous ducts were embedded within a dense sclerotic stroma imparting the appearance of an authentic incipient syringoma. This case also showed multifocal (2-3 foci) syringomatous lesions. In 1 case, syringomatous structures were colonized by the neoplastic cells from the EMPD (Fig. 4).
On immuhistochemical staining, syringoma-like structures were identified in 6 blocks from 4 patients. Staining for p63 highlighted the preserved native cells in the basal layer of the epidermis and in syringoma-like structures (Fig. 5A). Staining for CK7 revealed neoplastic cells, although the syringoma-like structures were negative (Fig. 5B).

\section{DISCUSSION}

Although glandular and pseudoglandular formations are well known features of EMPD, syringomatous structures in this condition have seldom been mentioned in the literature. Requena et $\mathrm{al}^{22}$ in their monograph on apocrine tumors of the skin in figure 38.10 document glandular elements naming them syringomatous structures. However, to our eyes, those glandular elements more likely represent neoplastic glands with an attenuated epithelial lining rather than a benign syringomatous lesion. The syringomatous structures we describe are different. Most seem to represent hyperplasia (and dilatation) of preexisting eccrine ducts, as these were clustered, and a connection to eccrine secretory lobules could be followed on serial sections. In 1 case, the syringomatous 
FIGURE 1. Clinical appearance of EMPD: Erythematous erosive areas (A, case 8 . B, case 3). Note small papules within the affected area and on normal skin (B). Histopathologically these represented infundibular cysts.
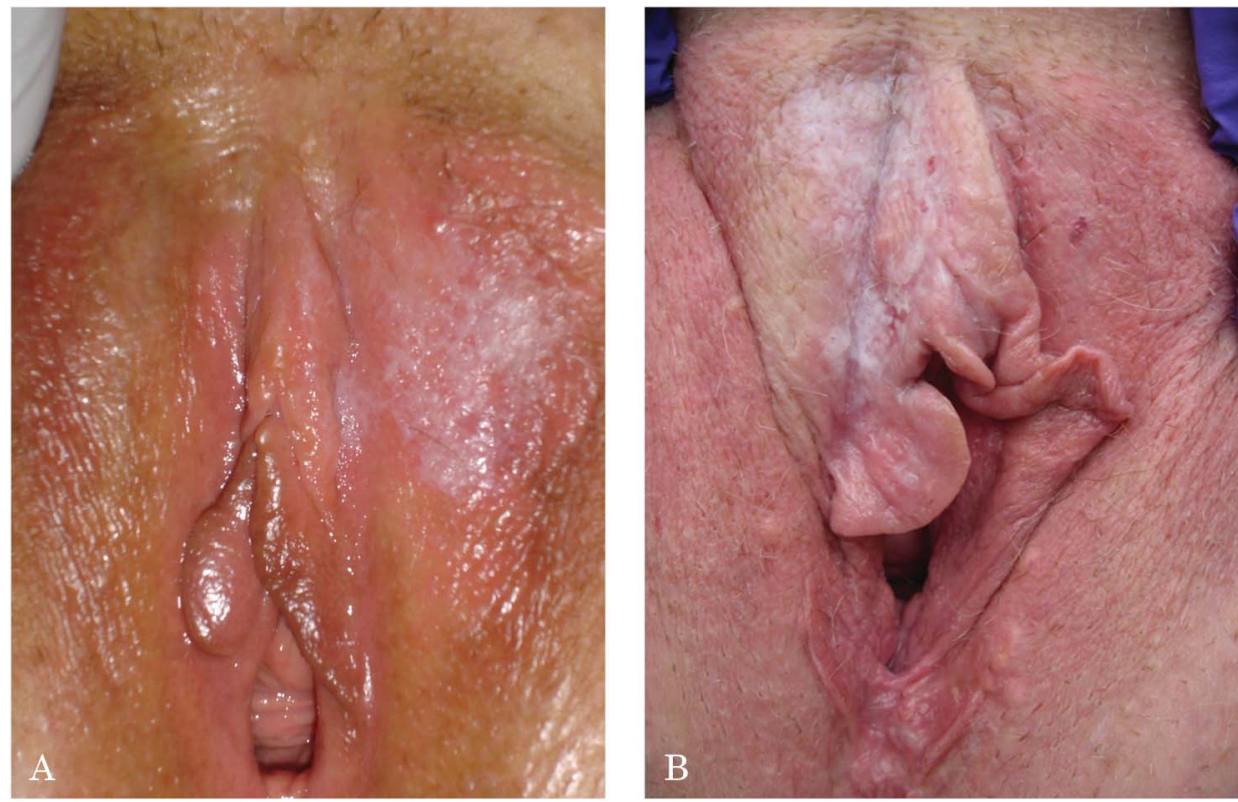

glands were embedded within a dense sclerotic stroma and the appearance was highly reminiscent of a small syringoma. Similar syringoma-like ductal proliferations are rarely found in different types of alopecia, especially scarring alopecia, but these are usually very small, focal, and are devoid of the typical sclerotic stroma that characterizes true syringoma. Although initially believed to represent true syringomas causing alopecia, these ductal proliferations were later presumed to be a reactive process secondary to the surrounding inflammation and dermal fibrosis. ${ }^{23-27}$ It has been suggested that these ductal proliferations are the result of destruction of the acrosyringium by lymphoid infiltration ("autoimmune

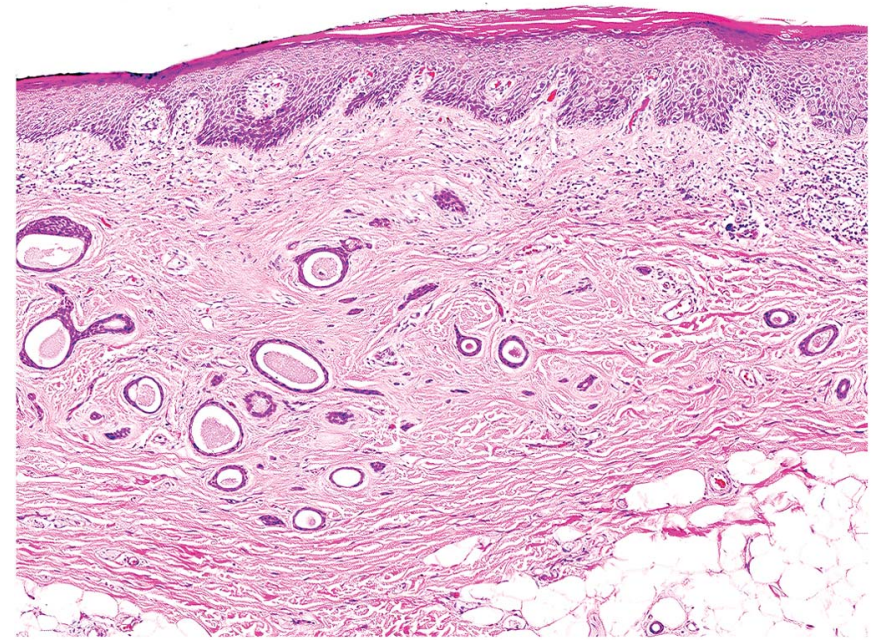

FIGURE 2. Syringoma-like structures in EMPD: Small ductal structures lined by bland-looking epithelial cells. Note tadpolelike appearances and sclerotic stroma reminiscent of syringoma. Intraepidermal carcinoma cells are evident above the lesion.

Copyright (C) 2016 Wolters Kluwer Health, Inc. All rights reserved. acrosyringitis") resulting in loss of structural continuity of the acrosyringium followed by secondary proliferation of the disrupted ducts. ${ }^{28}$ Other inflammatory and neoplastic conditions in which syringomatous ductal proliferations have been reported include Grover disease, leukemia cutis, prior irradiation, reexcision specimens, and prurigo nodularis. ${ }^{29-32}$ We presume that persistent rubbing, excoriation, and blockage of the intraepidermal acrosyringia by the EMPD may all contribute to the disruption and secondary hyperplasia/dilatation of eccrine ducts to form syringomatous structures.

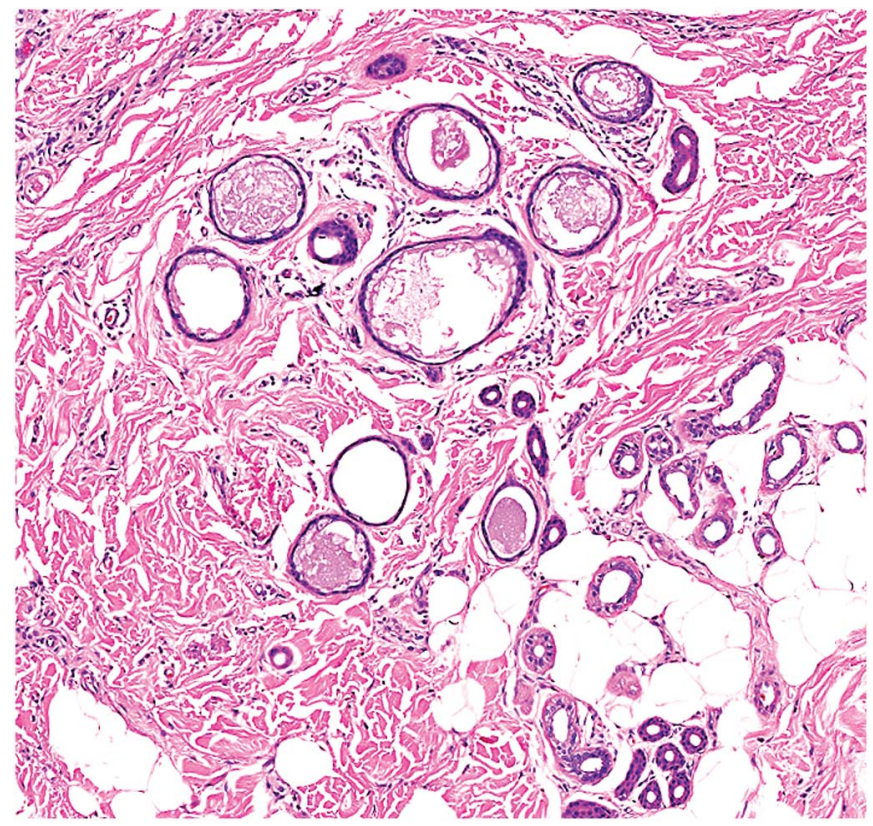

FIGURE 3. Connection of syringomatous structures to an eccrine secretory unit suggests that these may represent hyperplastic and dilated eccrine ducts.

www.amjdermatopathology.com | 655 
FIGURE 4. Involvement of syringomatous structures by neoplastic cells (arrows).

Whatever their pathogenesis, the syringomatous structures in EMPD represent a diagnostic pitfall, which is actually 2-fold. First, they should not be mistaken for true invasive neoplastic glandular elements. However, as demonstrated by our case 7 , these syringomatous glands may themselves be colonized by the neoplastic cells from the EMPD and perhaps serve as a conduit for the malignant cells to spread into the deeper regions of the dermis. Adnexotropism of neoplastic cells in EMPD is well known. ${ }^{10}$ In some cases of EMPD, we observed foci in which the neoplastic cells invaded the stroma from involved adnexal structures (hair follicles, apocrine, and eccrine glands) deep in the dermis. This pattern contrasts with the type of microinvasion defined by Feuer et $\mathrm{al}^{33}$ who

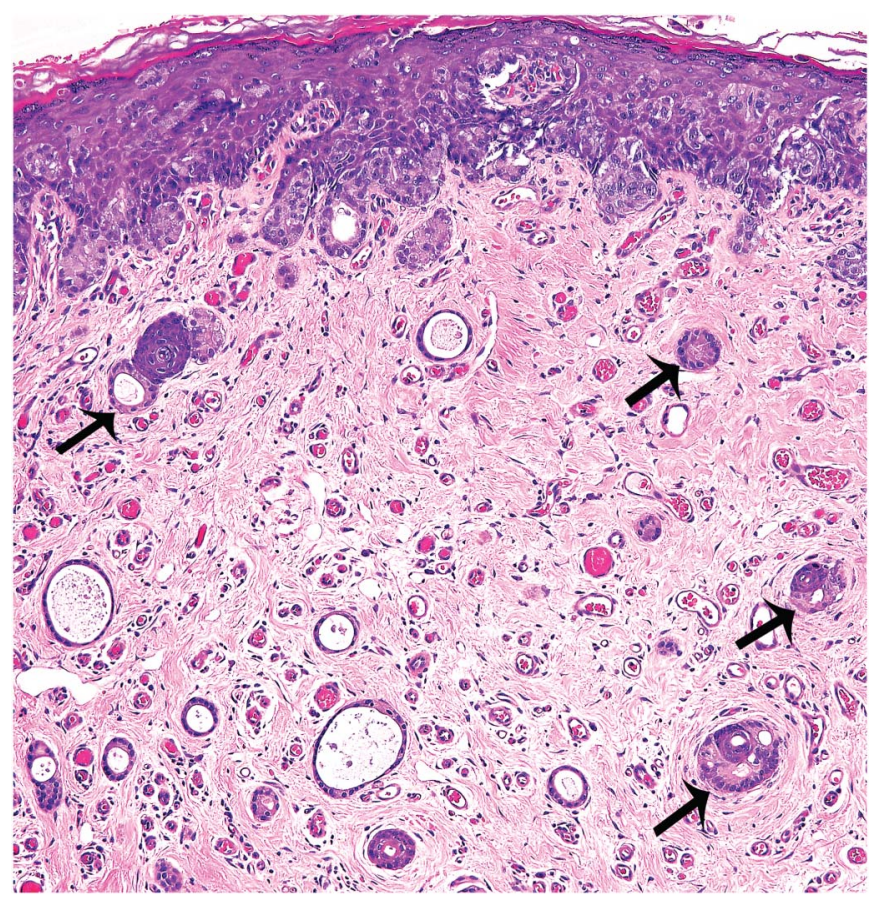

described invasion by the neoplastic elements to a depth of no more than $1 \mathrm{~mm}$ below the basement membrane of the surface epithelium. Such invasion from involved adnexal structures is similar to the pattern seen in carcinoma of the cervix, where microinvasion from involved endocervical glands is not uncommon.

The spectrum of EMPD includes cytologic variations in the neoplastic cells, single cell distribution and nested patterns, proliferative epidermal lesions, syringocystadenocarcinoma papilliferum in situ like areas, and hyperpigmented forms, rarely with melanocytic hyperplasia. ${ }^{16,21}$ A single case of EMPD with oncocytic changes has been described. ${ }^{34}$ The syringomalike structures reported here extend the morphological spectrum
FIGURE 5. p63 and CK7 immunostaining of syringoma-like structures in EMPD. A, Staining for p63 highlights the preserved native cells in the basal layer of the epidermis and in syringoma-like structures. B, Staining for CK7 reveals neoplastic cells while syringoma-like structures are negative.
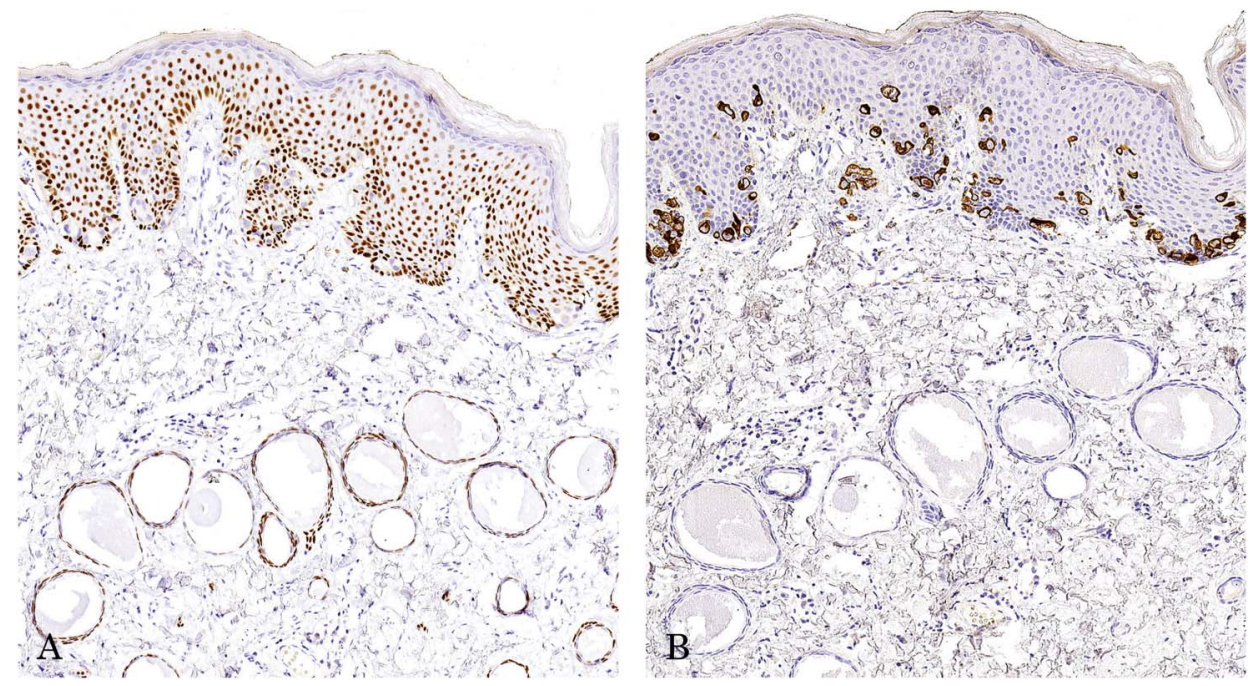

Copyright (C) 2016 Wolters Kluwer Health, Inc. All rights reserved. 
of EMPD, and awareness of these structures is important to avoid their misinterpretation as an invasive component of the carcinoma.

\section{REFERENCES}

1. Guarner J, Cohen C, DeRose PB. Histogenesis of extramammary and mammary Paget cells. An immunohistochemical study. Am J Dermatopathol. 1989;11:313-318.

2. Hamm H, Vroom TM, Czarnetzki BM. Extramammary Paget's cells: further evidence of sweat gland derivation. J Am Acad Dermatol. $1986 ; 15: 1275-1281$.

3. Lloyd J, Flanagan AM. Mammary and extramammary Paget's disease. $J$ Clin Pathol. 2000;53:742-749.

4. Mazoujian G, Pinkus GS, Haagensen DE Jr. Extramammary Paget's disease-evidence for an apocrine origin. An immunoperoxidase study of gross cystic disease fluid protein-15, carcinoembryonic antigen, and keratin proteins. Am J Surg Pathol. 1984;8:43-50.

5. Merot Y, Mazoujian G, Pinkus G, et al. Extramammary Paget's disease of the perianal and perineal regions. Evidence of apocrine derivation. Arch Dermatol. 1985;121:750-752.

6. Mitsudo S, Nakanishi I, Koss LG. Paget's disease of the penis and adjacent skin: its association with fatal sweat gland carcinoma. Arch Pathol Lab Med. 1981;105:518-520.

7. Nadji M, Morales AR, Girtanner RE, et al. Paget's disease of the skin. A unifying concept of histogenesis. Cancer. 1982;50:2203-2206.

8. Tsunemi Y, Saeki H, Kikuchi K, et al. Extramammary Paget's disease with intracytoplasmic lumen formation. J Dermatol. 2009;36:649-653.

9. Belousova IE, Kazakov DV, Michal M, et al. Vulvar Toker cells: the long-awaited missing link: a proposal for an origin-based histogenetic classification of extramammary paget disease. Am J Dermatopathol. 2006;28:84-86.

10. Urabe A, Matsukuma A, Shimizu N, et al. Extramammary Paget's disease: comparative histopathologic studies of intraductal carcinoma of the breast and apocrine adenocarcinoma. J Cutan Pathol. 1990;17:257-265.

11. van der Putte SC. Anogenital "sweat" glands. Histology and pathology of a gland that may mimic mammary glands. Am J Dermatopathol. 1991; 13:557-567.

12. van der Putte SC. Mammary-like glands of the vulva and their disorders. Int J Gynecol Pathol. 1994;13:150-160.

13. van der Putte SC. Clear cells of Toker in the developing anogenital region of male and female fetuses. Am J Dermatopathol. 2011;33:811-818.

14. Willman JH, Golitz LE, Fitzpatrick JE. Vulvar clear cells of toker: precursors of extramammary Paget's disease. Am J Dermatopathol. 2005; 27:185-188.

15. Di Bonito L, Patriarca S, Falconieri G. Aggressive "breast-like" adenocarcinoma of vulva. Pathol Res Pract. 1992;188:211-214; discussion 214-216.
16. Kazakov DV, Spagnolo DV, Kacerovska D, et al. Lesions of anogenital mammary-like glands: an update. Adv Anat Pathol. 2011;18:1-28.

17. Ohira S, Itoh K, Osada K, et al. Vulvar Paget's disease with underlying adenocarcinoma simulating breast carcinoma: case report and review of the literature. Int J Gynecol Cancer. 2004;14:1012-1017.

18. Piura B, Gemer O, Rabinovich A, et al. Primary breast carcinoma of the vulva: case report and review of literature. Eur J Gynaecol Oncol. 2002; 23:21-24.

19. Kazakov DV, Bouda J Jr, Kacerovska D, et al. Vulvar syringomas with deep extension: a potential histopathologic mimic of microcystic adnexal carcinoma. Int J Gynecol Pathol. 2011;30:92-94.

20. Huang YH, Chuang YH, Kuo TT, et al. Vulvar syringoma: a clinicopathologic and immunohistologic study of 18 patients and results of treatment. J Am Acad Dermatol. 2003;48:735-739.

21. Kazakov DV, Michal M, Kacerovska D, et al. Cutaneous Adnexal Tumors. Philadelphia, PA: Lippincot Williams and Wilkins; 2012.

22. Requena L, Kiryu H, Ackerman AB. Neoplasms with Apocrine Differentiation. Philadelphia, PA: Lippincott-Raven; 1998.

23. Barnhill RL, Goldberg B, Stenn KS. Proliferation of eccrine sweat ducts associated with alopecia areata. J Cutan Pathol. 1988;15:36-39.

24. Guitart J, Rosenbaum MM, Requena L. "Eruptive syringoma": a misnomer for a reactive eccrine gland ductal proliferation? J Cutan Pathol. 2003;30:202-205.

25. Mehregan AH, Mehregan DA. Syringoma-like sweat duct proliferation in scalp alopecias. J Cutan Pathol. 1990;17:355-357.

26. Requena L, Yus ES, Simon P, et al. Induction of cutaneous hyperplasias by altered stroma. Am J Dermatopathol. 1996;18:248-268.

27. Shelley WB, Wood MG. Occult syringomas of scalp associated with progressive hair loss. Arch Dermatol. 1980;116:843-844.

28. Chandler WM, Bosenberg MW. Autoimmune acrosyringitis with ductal cysts: reclassification of case of eruptive syringoma. J Cutan Pathol. 2009;36:1312-1315.

29. Amin SP, Herman AR, Busam KJ, et al. Multiple subclinical syringomatous proliferations encountered during mohs surgery for basal cell carcinoma. Dermatol Surg. 2004;30:1420-1423.

30. Corredor F, Cohen PR, Tschen JA. Syringomatous changes of eccrine sweat ducts associated with prurigo nodularis. Am J Dermatopathol. 1998;20:296-301.

31. Garcia-Rio I, Delgado-Jimenez Y, Aragues M, et al. A case of Grover's disease with syringoma-like features and leukemia cutis. J Cutan Pathol. 2006;33:443-446.

32. Yoshii N, Kanekura T, Churei H, et al. Syringoma-like eccrine sweat duct proliferation induced by radiation. $J$ Dermatol. 2006;33:36-39.

33. Feuer GA, Shevchuk M, Calanog A. Vulvar Paget's disease: the need to exclude an invasive lesion. Gynecol Oncol. 1990;38:81-89.

34. Aneiros-Fernandez J, Arias-Santiago S, Husein-ElAhmed H, et al. Extramammary Paget disease of scrotum with oncocytic changes. Am J Dermatopathol. 2010;32:723-726. 